International Journal of Engineering \& Technology, $7(2.29)(2018) 374-378$
International Journal of Engineering \& Technology
SPC
Website: www.sciencepubco.com/index.php/IJET
Research paper

\title{
Rural Community-Based Tourism Development in Bangladesh: The Conceptual Issues
}

\author{
Md. Afjal Hossain ${ }^{1 *}$, Uchinlayen ${ }^{1}$ \\ ${ }^{1}$ Deparment Of Tourism and Hospitality Management, University Of Dhaka, Bangladesh \\ *Corresponding Author E-Mail:Afjaldu@Hotmail.Com
}

\begin{abstract}
The concept of rural tourism can revitalize the conventional concepts of tourism, and bring socio-economic and environmental wellbeing of the rural community ensuring sustainable development of a particular country. The aim of this paper is to identify the prospects and problems of rural community-based tourism development in Bangladesh. Rural tourism is one of the most promising tourism sectors in Bangladesh. It can bring economic, social and environmental benefits to the community people. Development of the rural tourism will have a significant impact on the GDP and employment opportunities for them who are involved in its development process. This paper finds out some barriers of rural community-based tourism development and provides some suggestions to overcome those challenges. For the development of this promising sector, it needs proper policy formation, infrastructure development, human resource development, enough investment for services and facilities in the destination areas, readiness of rural people to arrange tourism in their areas, public private partnership, sustainable tourism development guidelines, etc. Finally, this paper also looks into at how rural community people of Bangladesh can be involved in the development of tourism activities in their own areas.)
\end{abstract}

Keywords: Rural Tourism; Community Involvement; Bangladesh

\section{Introduction}

Since the independence, the government of Bangladesh has been giving due attention on some important sectors like agriculture, manufacturing, infrastructure, readymade garments, service sector, etc. But tourism, as an important income generating sector, has failed to draw proper attention of the concerned authorities in Bangladesh. Rural tourism development in Bangladesh is not at all considered at any level, either in public or in private sector. The National Tourism Policy of 1992 and 2010 did not also consider the rural natural beauty and landscape and the development of tourism there. "But the development of a strong concept on rural tourism development involving the community there is definitely useful for a country like Bangladesh. Because, three-fourths of its population lives in rural areas. (1)." Bangladesh has huge potentials to flourish its rural tourism sector and contribute to community development through job creation, empowerment of local people, production of agro-products, and protection of environment, society, culture, etc. Bangladesh, endowed with green countryside, villages, cannels, rivers, birds, flora $\&$ fauna, rich and diversified customs and traditions, cultures, colorful festivals, folk arts and handicrafts as well as historical heritage, can definitely take advantage of developing rural tourism and community. Although the concept of rural tourism development through involving the community might be a bit of surprise to most of Bangladeshis, still the rural manner or hospitality of rustic people hold greater appeal to foreigners and $3 \ldots \ldots \ldots \ldots$ attract them in this county. The development of tourism activities in and around emerging locations of rural areas will ensure the community involvement for their livelihood. Experiences, lessons and guidelines of other developed and developing countries should be taken into consideration while developing this form of tourism in Bangladesh. "The situation requires a lot of careful study and strategic planning as local communities are a basic element of modern tourism development. Because they are the focal point for the supply of accommodation, catering, information, transport, facilities and services for tourism industry (2)". The socio-economic and cultural aspects of rural communities and environmental aspects of the locality concerned should be given due emphasis for rural tourism development and community involvement. By developing proper infrastructure, making intelligent planning, building public-private cooperation, making required investment and creating mass awareness in the country, a revolutionary change can be made in the tourism sector of Bangladesh (3).

\section{Objective of the Study}

1. To get a conceptual idea on rural tourism and its development through community involvement in Bangladesh;

2. to find out the impact of rural community-based tourism development on the local community in Bangladesh;

3. to identify the barriers of rural community-based tourism development in Bangladesh; and

4. to provide some guidelines for the development of rural tourism in Bangladesh and the involvement of local community in tourism activities. 


\section{Methodology}

This study is basically conceptual in nature. Qualitative analysis has been conducted based on the relevant issues and secondary information to understand the concept of rural tourism development through the community involvement in Bangladesh. For the purpose of analysis the data have been collected mainly from different publications of Bangladesh Parjatan Corporation (BPC), Bangladesh Tourism Board (BTB), Bangladesh Bank, Bangladesh Bureau of Statistics, World Tourism Organization, and World Travel and Tourism Council. Besides, books, journal articles, daily newspapers, websites, etc. have also been used extensively.

\section{Literature review}

The available and relevant literatures on this area have been reviewed and summarized here. (4) identified some communitybenefits that rural community-based tourism can bring. These include extra job opportunities, enhanced income, diversified local economic base, added cultural opportunities and additional tax revenues for government. (5) found both positive and negative impacts of rural tourism on the communities in Thailand. He emphasized the importance of sound planning like assessment of carrying capacity, development of infrastructure, zoning, involvement of local people, and educating both local people and tourists. Aref and Gill(6) realized that rural tourism can help alleviate poverty in rural areas. They also looked at how rural cooperatives can develop tourism in the rural areas. Sarkar(7) explore that the growth of rural tourism in West-Bengal of India ensures sustainable development of rural societies. He suggested for establishing an effective framework to develop rural tourism in a responsible manner. Chaudhry and Gupta (8) reported that $75 \%$ of the world's poor live in rural areas and that rural tourism is a tool for rural revitalization. Tuhin and Majumder (9) identified some elements like economic, environmental, cultural, and political issues of a particular place that encourage private enterprises to operate in tourism activities which again promote rural tourism. In investigating the role of tourism micro-enterprises in alleviating poverty of rural Bangladesh, Islam and Carlsen (10) found that local people are reluctant to switch from their traditional occupation to tourism activities. This works as an impediment to get the local community involved with tourism. Obonyo and Fwaya(11) found that potential villages having natural and socio-cultural appeal can attract the attention of both tourists and tourism planners. The study suggested integrating tourism with rural development strategies to ensure maximum benefits for the community. Chiutsi (12) in his paper showed that a higher level of communitybased tourism entrepreneurship leads to greater socio-economic benefits for majority of residents leading to biodiversity conservation and sustainable tourism development. Michael, Mgonja and Backman(13) examined the nature of community participation in decision-making process for tourism development and found it to be a guaranteed determinant in ensuring the benefits for lifestyles, values and respects of communities. Zhang el al., (14) summarized the pros and cons of rural tourism development. They suggested for avoiding or minimizing the adverse impacts of tourism, mitigating the conflicts between resources and development options, finding a balance between tourism development and rural construction, and realizing a win-win tourism development for rural construction. Ahmed and Jahan(1) identified that rural tourism benefits the rural communities socially, economically, and environmentally in a sustainable way. This study highlighted the prospects of rural tourism development in rustic Bengal. Jaafar, Bakri and Rasoolimanesh(15) explored how the local community perceives their involvement in local tourism development and increases its economic viability, and stimulates their social regeneration and living conditions.

\section{Research gap}

A review of rural tourism literatures highlights the paucity of studies in Bangladesh from the rural and community perspectives. This readily lends itself to a detailed exploration of the same. In Bangladesh, tourism was identified as a thrust sector, but very few papers have focused on the rural community-based tourism issues. Among the papers, $(9,10)$ are remarkable. These studies did not even highlight how to involve the local community with tourism activities and enhance their socio-economic conditions. As such, the present study deserves an utmost importance for the present day purpose of tourism development in the country.

\section{Analysis of Findings}

\section{1. the Concept of Rural Community Based Tourism}

Rural tourism means tourism taking place in the countryside. It represents the life, art, culture, nature, environment, historical places and heritage at rural places. It also means, agro-tourism, soft-tourism solidarity-tourism and even eco-tourism (16). It focuses agriculture and farms as the foundation upon which the attraction is built (17). The main theme of this tourism includes the uses of land in the countryside and culture of rural people. It creates an interaction between human being and the land of rural areas. It also includes cultural and heritage tourism, nature tourism and adventure tourism.

Rural community-based tourism means small scale tourism in rural areas, where the local community controls the operation and development of tourism activities. The community decides what they are willing to contribute and what they are not willing. (18). The goals and vision of tourism development are set in community meetings. For achieving the goals of improving the lives of communities through tourism initiatives, academic literature on sustainable tourism development has identified the need for community involvement in the planning and decision making process.

\subsection{Significance of Rural Tourism}

Rural tourism is a new concept benefitting the local community. It can benefit rural communities socially, economically, culturally and environmentally in a sustainable way (1). It provides income and employment for the community and enhances their socioeconomic dignity. Rural tourism is a viable means of promoting economic activity in both developed and developing countries (19). It also prevents local people to migrate to cities in search of employment. Rural young people leave villages and go to urban areas to find work for their livelihood. Very few of them come back to their villages. This triggers an increasing focu6s on rural community-based tourism by policy planners and communities as an alternative means of employment. It also enhances the environmental conditions of communities, because it focuses on sustainable tourism development.

Rural tourism benefits local communities through stimulating economic growth, valuing cultural heritage and raising their standard of living. These again encourage positive attitudes and behaviors of communities towards rural tourism development (15, 20).

Rural community-based tourism can benefit greatly from a targeted and integrated rural development program $(21,22)$. Rural tourism provides a befitting context to appraise and address development challenges specific to developing countries.

This type of tourism is attractive to investors, as it requires little capital and uses the existing unique local resources. As such, rural tourism enjoys substantial encouragement from both the public and private sectors (23).

Community involvement ensures community ownership, livelihood security, minimal leakages, conflict resolution and improved conservation (24). This is particularly true for developing coun- 
tries, where financial resources and expertise required may not be available at lower administrative levels (25).

\subsection{State of Rural Community-Based Tourism Devel- opment}

Rural tourism has drawn attention in recent time of many underdeveloped countries. But the development of rural tourism in Bangladesh is still in a take off stage which could be developed in a sustainable way involving the community.

Kerala (India) has implemented a project named United Nations Development Programme (GOI-UNDP) Endogenous Tourism Project (ETP), which spreads across 36 villages in India and focuses on the rural tourism experience, with thematic priorities that include human development, gender equality, strengthening decentralization, urban and rural livelihoods, energy and environment and vulnerability reduction(26).

Due to flourishing readymade garment sector in Bangladesh, a large portion of rural people have moved to urban areas for their livelihood. This has resulted in an imbalance in the development between rural and urban areas. As such, an additional source of income generation for the rural areas has become necessary. Rural community-based tourism can play an important position in this connection. But this has been overlooked by the concerned authorities in our country.

\subsection{Rural Tourism Development Impacts and Commu- nity Development}

Rural tourism has certain typical attributes like: it is based on experience, the locations are sparsely populated, it is predominantly in the natural setting, it meshes with seasonality and local events, and it is based on preservation of culture, heritage, nature, environment, society, community and traditions. It acts as an important force for developing rural areas. Having very little options for development, communities may evaluate rural tourism a great path for growth.

Rural tourism has important impacts on different areas like economy, society, politics, culture and environment in the rural areas. All these elements are interrelated for the development of community. Like other tourism activities, rural tourism results in a full range of environmental impacts (27). The figure below shows that community is the main point in the rural tourism development process though community involvement. Through rural tourism development everyone in the locality like local people, community, tourists, government, tour operators, stake holders are benefited directly or indirectly. Figure below represents the contributions of tourism in community.

Rural tourism alone is not a force to develop the countryside. It depends on the community, political wills of the government, socio-economic conditions of the country and environmental factors. Thus, a complex relationship exists among the community

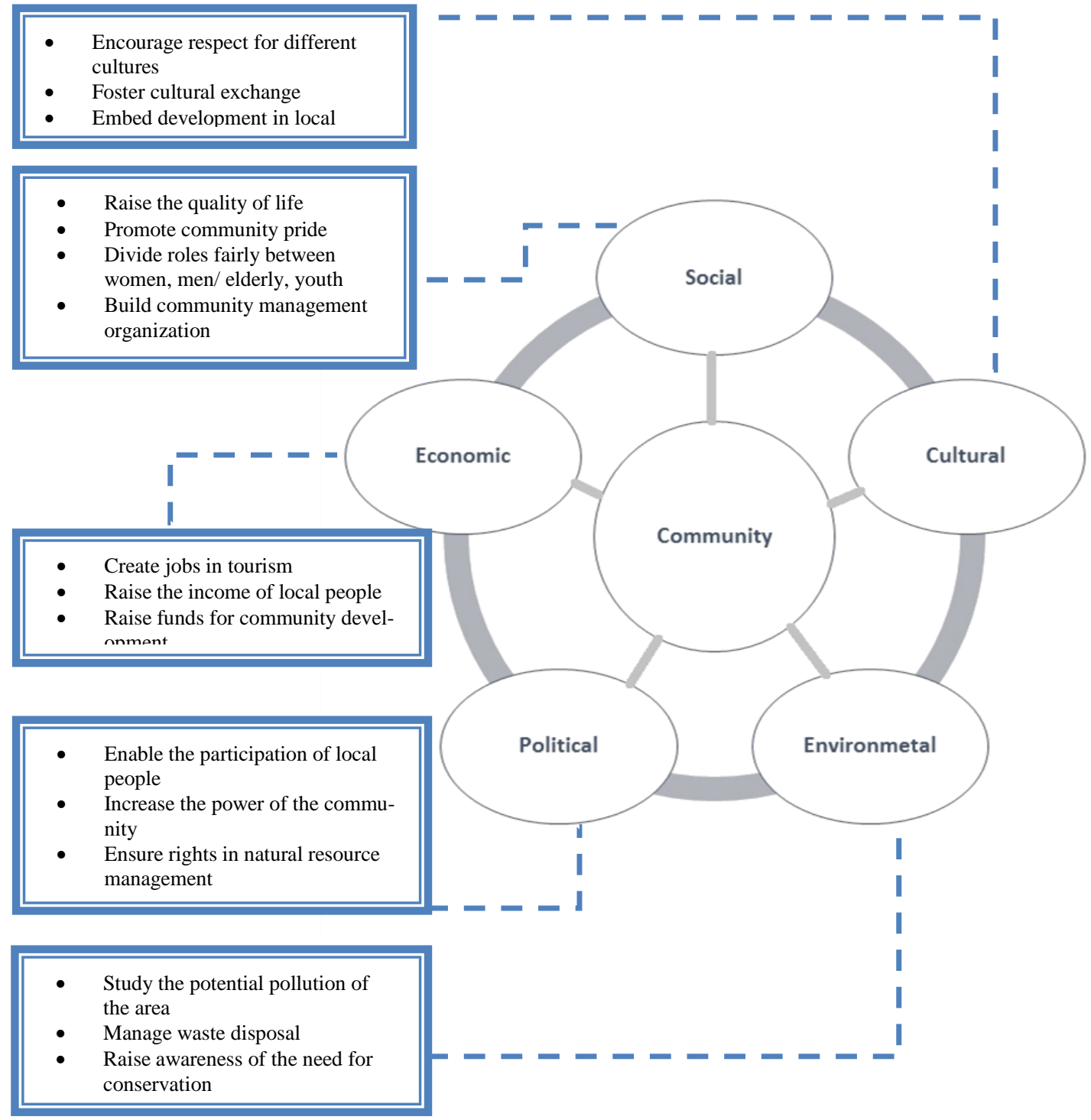

Fig. 1: Showing the Contribution of Tourism in Community. 
and other components of tourism activities. The earlier figure shows how rural tourism and the community are related with different socio-economic and cultural issues.

\subsection{Rural Community-Based Tourism Development In Bangladesh}

The involvement of Bangladesh community people in tourism activities is not significant. Because the involvement of the community people of Bangladesh is considered to be the most effective system for the development of rural Agriculture. But the rural tourism could be considered an economic alternative for rural areas facing decreasing agricultural profits and requiring a second or third economic footing (28). Rural tourism development in Bangladesh doesn't have a long history because of insufficient infrastructure, poor transportation system, lack of governments' initiatives and political unrest. Bangladesh definitely has the great opportunity for the development of rural and ecotourism tourism where community might be benefited. Evergreen nature, picturesque landscapes, thousands-years-old cultural and architectural heritages, hundreds of haors, baors, rivers and canals, delicious cuisine, inborn hospitality of rural people and their simplicity have made Bangladesh a unique destination. Besides, the flora- fauna, chirping-birds, rivers, closeness to the urban centers as well as the authentic character and rural charms are also important elements for the development of rural tourism in Bangladesh. But Bangladesh is not yet ready to welcome rural tourists. The development process of rural tourism around the heritage/archeological sites, improvement of rural infrastructure, creation of accessibility, establishment of standard accommodation and building of rural capacity for tourism development are not yet undertaken. Besides, the undefined role of the rural cooperatives in this industry, sociocultural and political barriers, and absence of human/economic resources, and the lack of government commitment are also responsible for not developing rural tourism in Bangladesh.

\subsection{Barriers of Rural Tourism Development}

Development: Bangladesh faces several barriers to the development of rural tourism. Following are the main barriers of rural tourism development in Bangladesh:

1. The rural community people are not still ready to involve themselves in tourism activities of their areas.

2. Inability of the community for the development of rura tourism.

3. Lack of research and guidelines for rural tourism development.

4. Lack of investment and entrepreneurial ability to participate in rural tourism.

5. Resource constraints for the development of rural tourism and community.

6. Lack of safety and security in the rural areas.

7. Poor country image due to political turmoil, corruption and terrorism.

8. Underdeveloped infrastructure and connectivity with the rural destinations.

Bushell and Eagles (29) again identified some more barriers to the development of rural tourism. Some of these are common in Bangladesh.

1. Lack of formal education and appropriate managerial training of local people.

2. Lack of foreign language skills

3. Dealing with hygienic food and water, litter and maintenance of infrastructure.

4. Limited knowledge of food preparation and services for foreigners.

5. Absence of planning skills for the development of and lack of ability to control tourism, unpredictable political climates, and uncertainty of long-term funding.

\section{Recommendations for Improvements}

The concept of rural tourism in Bangladesh is new. But it has huge potentials to draw the attention of policy makers. Understanding the barriers will help the community, stake holders and others in making proper policies in this regard. This will also help them overcome the barriers and thus develop rural community-based tourism in Bangladesh. It is, of course, challenging for the government and communities to tackle those obstacles and thus involve communities in the development process of tourism in rural areas. As such, the concerned authority of the country should take necessary initiatives to identify the barriers and take steps to tackle the barriers.

1. To make foreigners stay interesting and worth spending of their money.

2. Sanitation and hygienic food and water should be ensured for tourists.

3. Electricity, telephone and wayside amenities should be provided.

4. Sufficient training has to be given to the employees, executives and local people in order to offer standard services.

5. Languages training courses like English, French, German, and Chinese should be conducted to develop communication skills among employees.

6. Improved transport to be provided to make the destinations easily accessible.

7. Local culture and natural heritage sites should be presented intelligently to provide tourists memorable experience.

8. Historical and archaeological sites, ancient buildings and monuments and the sights of natural importance should be conserved and protected from physical deterioration.

9. Security measures should be strengthened to ensure safe and risk-free movements of the local and foreign tourists in rural areas.

10. Tourism fairs should be arranged focusing on the unspoiled natural beauty, village charms and rural landscape of Bangladesh.

11. Women should be involved in rural tourism to alleviate their poverty.

12. Local dances and music of both the traditional Bengali artists and the tribes should be arranged regularly at the rural destination areas.

13. Services like food, guide and presentation of local culture are necessary to attract both domestic and foreign tourist.

14. Rural way of living, hospitality of people, local foods, rural culture and rural arts and crafts should be presented intelligently to the tourists.

15. Proper marketing approaches and promotional activities should be strengthened to remove the perceived negative image of and misconceptions about Bangladesh before the arrival of the tourists in Bangladesh

16. Government should encourage private and foreign investments in the rural tourism arena through formulating liberal government policies, granting loans on easy terms, allowing tax holidays and providing physical facilities.

17. To ensure sustainability in rural tourism sector, private enterprise should be active in "green marketing" and creating a type of tourism that conform both tourists' expectations and industry standards.

18. Alternative laws are necessary to promote rural tourism and protect the nature in the tourist destination.

Government and the policy makers should really be sincere to develop rural tourism in Bangladesh. They should come up with action-based approaches. More budgets should be allocated to develop rural infrastructure, facilities, services and manpower to 
handle tourism activities smoothly in the rural areas of Bangladesh. "International tourist arrivals reached 1.14 billion in 2014. Travel \& Tourism generated US\$ 7.58 trillion (9.8\% of global GDP) and 277 million jobs ( 1 in 11 jobs or $9.4 \%$ of total employment) for the global economy in 2014. Travel \& Tourism has attracted investment of US\$ 814.4 billion in 2014. (30).”

\section{Conclusion}

The concept of rural community-based tourism development is still to conceive by Bangladesh. The country is filled with thousands of villages with their unique beauties and charms. Though it has a lot of opportunities to flourish, rural tourism in Bangladesh is in a take off stage and has been growing at a very slow pace. Bangladesh has many opportunities to develop its rural tourism because she has a unique features, sights, and charms that the universe is yet to explore and experience. If a proper marketing plan is taken for rural tourism development, it could bring lots of benefit to our country and can be an important mechanism for sustainable human development including poverty alleviation, employment generation, development of rural areas and progression of women and other disadvantaged groups in the country. But it is definitely true that the development plan must require caution. Rural art, culture, music, dance drama, life style and tradition, cuisine should be the integral part of rural tourism. That is, rural community-based tourism should be functionally rural and traditional in character.

\section{References}

[1] Ahmed I, Jahan N. Rural Tourism-Prospects in Rustic Bengal European Journal of Business and Management, ISSN. 2013:22221905.

[2] Godfrey K, Clarke J. The tourism development handbook: a practical approach to planning and marketing: Burns \& Oates; 2000

[3] Afroz N, Hasanuzzaman M. Problems and Prospects of Tourism in Bangladesh: Bandarban District Case. Global Journal of Management and Business Research. 2012;12(23):1-9.

[4] Weaver G. Tourism development: a potential for economic growth 1986.

[5] Rattanasuwongchai N. Rural Tourism-the impact on rural communities II. Thailand [Electronic Version] Retrieved December. 1998;7:2009.

[6] Aref F, Gill SS. Rural tourism development through rural cooperatives. Nature and Science. 2009;7(10):68-73.

[7] 7. Sarkar S. Rural Tourism Prospects in West Bengal Province. Berjaya University College of Hospitality Kuala Lumpur. 2009.

[8] Chaudhry P, Gupta RK. Urban greenery and its sustainable extension strategies in hot arid region of India. International Journal of Sustainable Society. 2010;2(2):146-55.

[9] Tuhin MKW, Majumder MTH. An Appraisal of Tourism Industry Development in Bangladesh. European Journal of Business and Management. 2011;3(3):287-97.

[10] Islam F, Carlsen J. Tourism in rural Bangladesh: Unlocking opportunities for poverty alleviation? Tourism Recreation Research 2012;37(1):37-45.

[11] Obonyo GO, Fwaya EVO. Integrating tourism with rural development strategies in western Kenya. Citizen Participation in Decision Making: Towards Inclusive Development in Kenya. 2014:160.

[12] Chiutsi S, Mudzengi BK. Community tourism entrepreneurship for sustainable tourism management in Southern Africa: Lessons from Zimbabwe. International Journal of Academic Research in Business and Social Sciences. 2012;2(8):127.

[13] Michael M, Mgonja JT, Backman KF. Desires of community participation in tourism development decision making process: A case study of Barabarani, Mto Wa Mbu, Tanzania. American Journal of Tourism Research. 2013;2(1):84-94.

[14] Zhang C, Deng G, Yu X. The Influence of Tourism on Rural Life in Minority Areas. Applied Mathematics. 2013;4(08):1207.

[15] 15. Jaafar M, Bakri NM, Rasoolimanesh SM. Local community and tourism development: A study of rural mountainous destinations. Modern Applied Science. 2015;9(8):399.

[16] Beeton S. Community development through tourism: Landlinks Press; 2006.
[17] Knowd I, editor Rural tourism: panacea and paradox-Exploring the phenomenon of rural tourism and tourism's interaction with host rural communities. Geography Teachers' Curriculum Workshop, University of Western Sydney; 2001.

[18] Hatton MJ. Community-based tourism in the Asia-Pacific: School of Media Studies; 1999.

[19] Hall CM. Tourism and politics: policy, power and place: John Wiley \& Sons; 1994.

[20] Nunkoo R, Gursoy D. Residents' support for tourism: An identity perspective. Annals of Tourism Research. 2012;39(1):243-68.

[21] MoT. Ministry of Tourism, Government of India, Scheme for Rural Tourism 2002 [Available from: http://tourism.gov.in/.

[22] NPI. National Portal of India, Rural Development: General Overview 2010 [Available from: http://india.gov.in/sectors/rural/rural_overview.php.

[23] Fleischer A, Pizam A. Rural tourism in Israel. Tourism management. 1997;18(6):367-72.

[24] Spenceley A, Rozga Z, McKeeman J. Practical Initiatives in Responsible Tourism in Destinations 2008 [Available from: http://anna.spenceley.co.uk/.

[25] Nyaupane GP, Morais DB, Dowler L. The role of community involvement and number/type of visitors on tourism impacts: A controlled comparison of Annapurna, Nepal and Northwest Yunnan, China. Tourism management. 2006;27(6):1373-85.

[26] ERI. Endogenous Tourism Project Newsletter 2005 [Available from: http://exploreruralindia.org/HTML/news and events.php.

[27] Kuo N-W. Sustainable rural tourism development based on agricultural resources: the eco-inn initiative in Taiwan. International journal of agricultural resources, governance and ecology. 2008;7(3):229-42.

[28] Verma SK. Cooperatives and Tourism : An Asian Perspective 2008 [Available from: http://www.ica.coop/tica/cartagenaverma.pdf.

[29] Bushell R, Eagles PF. Tourism and protected areas: benefits beyond boundaries: the Vth IUCN World Parks Congress: CABI; 2006.

[30] WTTC. Travel \& Tourism Economic Impact 2015. 2015:1-16. 